\title{
Safety Profile of Baricitinib in Patients with Active Rheumatoid Arthritis with over 2 Years Median Time in Treatment
}

\author{
Josef S. Smolen, Mark C. Genovese (D), Tsutomu Takeuchi, David L. Hyslop, William L. Macias, \\ Terence Rooney, Lei Chen, Christina L. Dickson, Jennifer Riddle Camp, Tracy E. Cardillo, \\ Taeko Ishii, and Kevin L. Winthrop
}

\begin{abstract}
Objective. Baricitinib is an oral, once-daily selective Janus kinase (JAK1/JAK2) inhibitor for adults with moderately to severely active rheumatoid arthritis (RA). We evaluated baricitinib's safety profile through 288 weeks (up to September 1, 2016) with an integrated database [8 phase III/II/Ib trials, 1 longterm extension (LTE)].

Methods. The "all-bari-RA" group included patients who received any baricitinib dose. Placebo comparison was based on the 6 studies with $4 \mathrm{mg}$ and placebo up to Week 24 ("placebo- $4 \mathrm{mg}$ " dataset). Dose response assessment was based on 4 studies with $2 \mathrm{mg}$ and $4 \mathrm{mg}$ including LTE data ("2 mg-4 mg-extended"). The uncommon events description used the non-controlled all-bari-RA.

Results. There were 3492 patients who received baricitinib for 6637 total patient-years (PY) of exposure (median $2.1 \mathrm{yrs}$, maximum $5.5 \mathrm{yrs}$ ). No differences in rates of death, adverse events leading to drug discontinuation, malignancies, major adverse cardiovascular event (MACE), or serious infections were seen for $4 \mathrm{mg}$ versus placebo or for $4 \mathrm{mg}$ versus $2 \mathrm{mg}$. Infections including herpes zoster were significantly more frequent for $4 \mathrm{mg}$ versus placebo. Deep vein thrombosis/pulmonary embolism were reported with $4 \mathrm{mg}$ but not placebo [all-bari-RA incidence rate (IR) $0.5 / 100 \mathrm{PY}$ ]; the IR did not differ between doses ( 0.5 vs $0.6 / 100 \mathrm{PY}, 2 \mathrm{mg}$ vs $4 \mathrm{mg}$, respectively) or compared to published RA rates. All-bari-RA had 6 cases of lymphoma (IR 0.09/100 PY), 3 gastrointestinal perforations (0.05/100 PY), 10 cases of tuberculosis (all in endemic areas; 0.15/100 PY), and 22 all-cause deaths (0.33/100 PY). IR for malignancies (0.8/100 PY) and MACE $(0.5 / 100 \mathrm{PY})$ were low and did not increase with prolonged exposure.

Conclusion. In this integrated analysis of patients with moderate to severe active RA with exposure up to 5.5 years, baricitinib has an acceptable safety profile in the context of demonstrated efficacy. Trial registration numbers: NCT01185353, NCT00902486, NCT01469013, NCT01710358, NCT01721044, NCT01721057, NCT01711359, and NCT01885078 at clinicaltrials.gov. (First Release September 15 2018; J Rheumatol 2019;46:7-18; doi:10.3899/jrheum.171361)
\end{abstract}

Key Indexing Terms:

BARICITINIB SAFETY

RHEUMATOID ARTHRITIS

\section{JANUS KINASE INHIBITOR CLINICAL TRIALS}

From the Division of Rheumatology, Department of Medicine, Medical University of Vienna, Vienna, Austria; Division of Immunology and Rheumatology, Stanford University Medical Center, Palo Alto, California, USA; Division of Rheumatology, Department of Internal Medicine, Keio University, Tokyo, Japan; Lilly Research Laboratories, Eli Lilly and Co., Indianapolis, Indiana, USA; Lilly Research Laboratories, Eli Lilly and Co., Kobe, Japan; Oregon Health Sciences University, Portland, Oregon, USA.

This work was funded by Eli Lilly and Co., which manufactures baricitinib, and Incyte Corp. A related abstract and poster by all of the authors were presented at the 2017 American College of Rheumatology/

Association of Rheumatology Health Professionals Annual Meeting, November 3-8, San Diego, California, USA: "Safety Profile of Baricitinib for the Treatment of Rheumatoid Arthritis up to 5.5 Years: An Updated Integrated Safety Analysis."

J.S. Smolen, MD, Division of Rheumatology, Department of Medicine, Medical University of Vienna; M.C. Genovese, MD, Division of Immunology and Rheumatology, Stanford University Medical Center; T. Takeuchi, MD, PhD, Division of Rheumatology, Department of Internal Medicine, Keio University; D.L. Hyslop, MD, Lilly Research Laboratories, Eli Lilly and Co., USA; W. Macias, MD, PhD, Lilly Research
Laboratories, Eli Lilly and Co., USA; T. Rooney, MD, Lilly Research Laboratories, Eli Lilly and Co., USA; L. Chen, MD, PhD, Lilly Research Laboratories, Eli Lilly and Co., USA; C.L. Dickson, BS Pharm, Lilly Research Laboratories, Eli Lilly and Co., USA; J. Riddle Camp, BA, Lilly Research Laboratories, Eli Lilly and Co., USA; T.E. Cardillo, MSN, Lilly Research Laboratories, Eli Lilly and Co., USA; T. Ishii, MD, PhD, Lilly Research Laboratories, Eli Lilly and Co., Japan; K.L. Winthrop, MD, MPH, Oregon Health Sciences University.

Address correspondence to Prof. Dr. J.S. Smolen, Medical University of Vienna, Währinger Gürtel 18-20, Vienna, Austria.

E-mail:josef.smolen@meduniwien.ac.at

Full Release Article. For details see Reprints and Permissions at jrheum.org Accepted for publication July 1, 2018.

Rheumatoid arthritis (RA) treatment goals include controlling synovitis, improving and preserving physical function, and preventing joint damage and disability ${ }^{1}$. Despite availability of conventional synthetic and biological disease-modifying antirheumatic drugs (bDMARD), many

Personal non-commercial use only. The Journal of Rheumatology Copyright (c) 2019. All rights reserved. 
patients do not achieve remission/low disease activity, lose response over time, or have safety or tolerability issues, including infections ${ }^{2,3}$.

Janus kinase (JAK) inhibitors, which target cytokine signaling pathways implicated in RA pathogenesis $4,5,6$, offer an alternative treatment option. Baricitinib, an oral selective JAK1 and JAK2 inhibitor, demonstrated clinical efficacy with acceptable safety in phase III trials $7,8,9,10$.

Comprehensive evaluation across trials with a longer timeframe is necessary to fully understand a drug's safety profile. Here we characterize the safety profile of baricitinib by pooling data from available RA clinical trials, including a longterm extension (LTE) study.

\section{MATERIALS AND METHODS}

Study designs and patients. Patient-level data from 8 randomized clinical trials ( 4 phase III, 3 phase II, 1 phase Ib) and 1 ongoing LTE trial were included; data went up to September 1, 2016 (Table $1^{7-13}$ ). Eligible phase II/III trial patients were aged $\geq 18$ years with moderately to severely active RA. Exclusions included current or recent ( $<30$ days prior to study entry) clinically serious infection requiring antimicrobial treatment [including active or untreated latent tuberculosis (TB)] and selected laboratory abnormalities (hepatic/renal function tests, selected hematology, markers of infection). Evaluated baricitinib doses ranged from 1 to $15 \mathrm{mg}$ daily, with 2 and $4 \mathrm{mg}$ in phase III and the LTE. Trials were conducted in accordance with the Declaration of Helsinki and Good Clinical Practice guidelines, and were approved by each center's institutional review board (Supplementary Table 1 , available with the online version of this article). All patients provided written informed consent.

Patients completing phase III trials were eligible for the LTE study. Patients randomized to $2 \mathrm{mg}$ and not rescued in the originating study continued taking $2 \mathrm{mg}$ in the LTE; all other patients received $4 \mathrm{mg}$. Patients receiving $4 \mathrm{mg}$ for at least 15 months without rescue and achieving sustained low disease activity [Clinical Disease Activity Index (CDAI) score $\leq 10$ ] or remission (CDAI score $\leq 2.8^{14}$ ) were blindly re-randomized to $4 \mathrm{mg}$ or

Table 1. Patient populations.

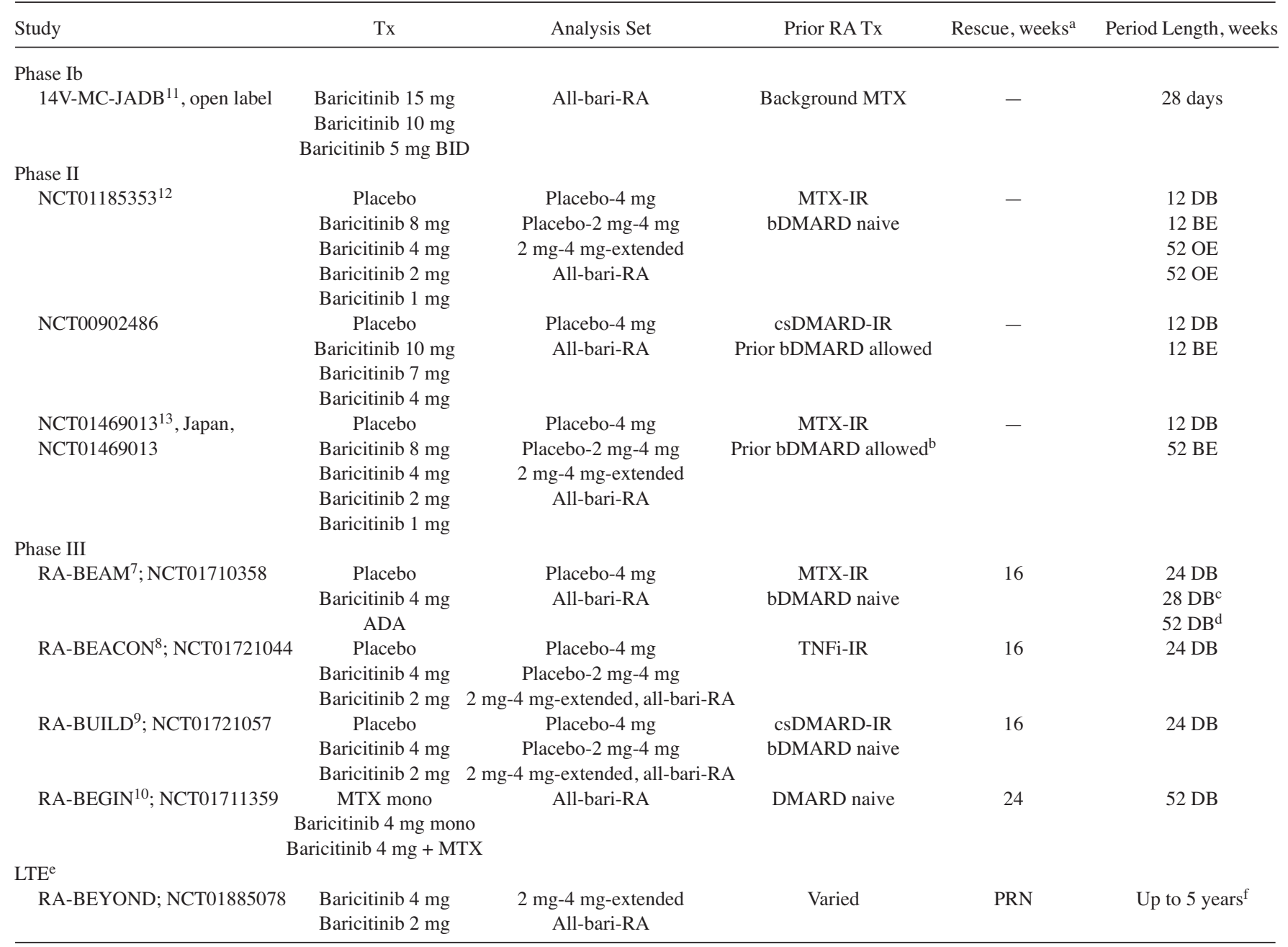

${ }^{a}$ First available rescue. ${ }^{b}$ Prior bDMARD allowable; however, patients could not have stopped treatment as a result of insufficient response. ${ }^{\mathrm{c}}$ Double-blind with no placebo. ${ }^{\mathrm{d}}$ Trial RA-BEAM had 24 weeks of placebo control and 52 weeks of active control. ${ }^{\text {e }}$ Studies contributing to LTE RA-BEYOND included phase II trial NCT01185353 and phase III trials RA-BEAM, RA-BEACON, RA-BUILD, and RA-BEGIN. ${ }^{\mathrm{f}}$ Ongoing trial with data as of September $1,2016$. RA: rheumatoid arthritis; IR: incidence rate; BID: twice daily; DB: double-blind; bDMARD: biological disease-modifying antirheumatic drug; BE: blinded extension with no placebo; csDMARD: conventional synthetic DMARD; ADA: adalimumab; LTE: longterm extension; MTX: methotrexate; OE: open-label extension; PRN: pro re nata (as needed); TNFi: tumor necrosis factor inhibitor. 
tapered down to $2 \mathrm{mg}$. Phase II NCT01185353 patients were also eligible for the LTE and were treated with $4 \mathrm{mg}$.

Analysis sets were organized as follows: (1) "Placebo- $4 \mathrm{mg}$ " was 6 studies with patients randomized to placebo or $4 \mathrm{mg}$ through 24 weeks of treatment. Data censored at rescue or end of placebo-controlled period ("as-treated" analysis); (2) "Placebo-2 mg-4 mg" was 4 studies with patients randomized to placebo, $2 \mathrm{mg}$, or $4 \mathrm{mg}$ up to 24 weeks of treatment. Data censored at rescue or end of placebo-controlled period; (3) "2 mg-4 mg-extended" was patients from placebo- $2 \mathrm{mg}-4 \mathrm{mg}$ plus data from extension periods. Data censored at rescue or dose change; (4) "All-bari-RA" was all patients who received at least 1 dose of baricitinib; includes all available data without censoring for rescue or dose change.

Analysis sets 1-3 ("as-treated") allowed randomized comparison between treatment groups. Primary analyses were based on placebo- $4 \mathrm{mg}$, the largest placebo-controlled set. Dose response evaluation for laboratory abnormalities was based on placebo- $2 \mathrm{mg}-4 \mathrm{mg}$, which allows analysis in the short term while avoiding potentially biased dose-response inferences from combining trials with and without a 2-mg arm. Dose response for adverse events (AE) was based on $2 \mathrm{mg}-4 \mathrm{mg}$-extended, which maximizes randomized dose comparison information. Because of the longterm latency period, malignancy [excluding nonmelanoma skin cancer (NMSC)] was also evaluated without censoring for rescue or dose change ("as-randomized" analysis $)^{15}$. Uncommon events were primarily evaluated using all-bari-RA. Although uncontrolled, data were not censored at dose change or rescue, which provides the largest patient-years (PY) of exposure. Lastly, to evaluate the longterm laboratory profile for DMARD-inadequate responders initially randomized to and maintained on $4 \mathrm{mg}$ (in RA-BEAM, RA-BEACON, RA-BUILD, NCT01185353, and the LTE), a "4-mg longterm cohort" was extracted from all-bari-RA.

Safety data for active comparators through 52 weeks [adalimumab (ADA; RA-BEAM); methotrexate (MTX; RA-BEGIN)] were previously reported $^{9,10}$, and except for deaths, are not included here.

Assessments. Safety assessments included treatment-emergent AE (TEAE), $\mathrm{AE}$ leading to temporary interruption or permanent discontinuation of study drug, serious AE (SAE), AE of special interest, and deaths. An SAE was any event meeting International Conference on Harmonisation E2A seriousness criteria $^{16}$.

Placebo and each baricitinib group were compared using the Cochran-Mantel-Haenszel test stratified by trial. Differences between doses were evaluated by Mantel-Haenszel incidence rate difference adjusting for trial. Exposure-adjusted incidence rates (EAIR) were calculated as the number of patients with an event per $100 \mathrm{PY}$ of overall exposure time. For $\mathrm{AE}$ of special interest, IR were calculated as the number of patients with an event per $100 \mathrm{PY}$ of observation time including any postdrug followup time, with observation time censored at event date.

\section{RESULTS}

Patients. Patient demographics including baseline age, steroid use, and disease severity were generally similar across treatment groups within analysis sets (Table 2). Most patients were female $(\sim 80 \%)$, with mean age $\sim 53$ years, $\sim 9$ years since RA diagnosis, and moderate or high baseline disease activity (CDAI $>10.0$ to 22.0 , or $>22.0$, respectively) ${ }^{17,18}$.

In all-bari-RA, 3492 patients received $\geq 1$ dose of baricitinib for a total of $6636.7 \mathrm{PY}$ exposure. A total of $78 \%$ of patients had $\geq 1$ year and $54 \%$ had $\geq 2$ years of treatment with a maximum exposure of 5.5 years (Table 3 ). Patients were treated for about $400 \mathrm{PY}$ in a placebo-controlled period, and about $187 \mathrm{PY}$ in placebo- $2 \mathrm{mg}-4 \mathrm{mg}$. In $2 \mathrm{mg}-4 \mathrm{mg}$-extended, $4 \mathrm{mg}$ had greater PY than $2 \mathrm{mg}$, and more $4 \mathrm{mg}$ patients had $\geq 1$ years of exposure with similar $\geq 2$ years (Table 3 ).
$A E$, including $S A E$. The SAE EAIR was similar between groups in placebo-4 mg (12.7 vs 12.9) and numerically higher for $4 \mathrm{mg}$ compared to $2 \mathrm{mg}$ in $2 \mathrm{mg}-4 \mathrm{mg}$-extended (13.2 vs 10.1; Table 3). No single system organ class appeared to account for this difference.

Thirty-one deaths occurred in the baricitinib RA program. Two deaths (myocardial infarction) occurred during screening and were not considered related to study procedures. Three deaths occurred among placebo-treated (PY $=393.8$, IR 0.76) and 4 deaths among active-comparatortreated patients $(\mathrm{PY}=447.4$, IR 0.89). Twenty-two deaths (causes of death, Table 3, footnote c) occurred among all baricitinib-treated patients ( $\mathrm{PY}=6636.7$, IR 0.33 (95\% CI $0.2-0.5)$.

The incidence for temporary interruption or permanent discontinuation of study drug due to an AE was numerically higher for $4 \mathrm{mg}$ compared to placebo (Table 3), most frequently due to infections (Table 4). The most common infection leading to discontinuation was herpes zoster, for which all phase III - but not LTE - protocols required discontinuation. Some laboratory changes were reported by the investigator as $\mathrm{AE}$ and are included in Table 4; Table $5^{19,20}$ shows details on select laboratory changes based on central laboratory testing.

$A E$ of special interest. Infection was the most common TEAE in placebo-4 mg and was more frequent in $4 \mathrm{mg}$ (EAIR 88.4 vs $75.9,36.3 \%$ vs $27.9 \%$ of patients). The higher infection EAIR for $4 \mathrm{mg}$ compared to placebo (Table 3 ) is attributed to a higher incidence of upper respiratory tract infections (EAIR 44.7 vs $39.4,18.4 \%$ vs $14.5 \%$ of patients), herpes zoster (4.3 vs $1.0,1.8 \%$ vs $0.4 \%$ of patients), and herpes simplex (5.4 vs $2.5,2.2 \%$ vs $0.9 \%$ of patients). In $2 \mathrm{mg}-$ $4 \mathrm{mg}$-extended, the TE infection EAIR was comparable between doses. The serious infection IR was similar between treatment groups across sets. The placebo- $4 \mathrm{mg}$ IR was 4.2 vs 3.8 (Table 3 ). The all-bari-RA IR was 2.9 (95\% CI 2.5-3.4) and the most common serious infections were pneumonia $(\mathrm{n}=36$, EAIR 0.5), herpes zoster $(\mathrm{n}=26$, EAIR $0.4)$, urinary tract infection ( $\mathrm{n}=18$, EAIR 0.3 ), and cellulitis $(\mathrm{n}=10$, EAIR 0.1). Serious infection rates in patients who were taking glucocorticoids at baseline were about twice those seen in those not taking glucocorticoids; importantly, however, this was seen not only for patients receiving baricitinib but also with placebo (data not shown).

Ten TB cases were reported in all-bari-RA (IR 0.15, 95\% CI 0.07-0.27; Table 3). All occurred in endemic areas (Argentina, India, Russian Federation, South Africa, South Korea, and Taiwan). One case occurred in the placebo-controlled period, 1 following rescue from placebo to $4 \mathrm{mg}$, and 8 after LTE entry.

The herpes zoster IR was significantly higher for $4 \mathrm{mg}$ compared to placebo (4.3 vs 1.0) and for $4 \mathrm{mg}$ compared to $2 \mathrm{mg}$ in $2 \mathrm{mg}-4 \mathrm{mg}$-extended (Table 3). The all-bari-RA IR was 3.2 (95\% CI 2.8-3.7). All cases were cutaneous. Nearly

Personal non-commercial use only. The Journal of Rheumatology Copyright $\subset$ (2019. All rights reserved. 
Table 2. Baseline demographics and measures of disease activity.

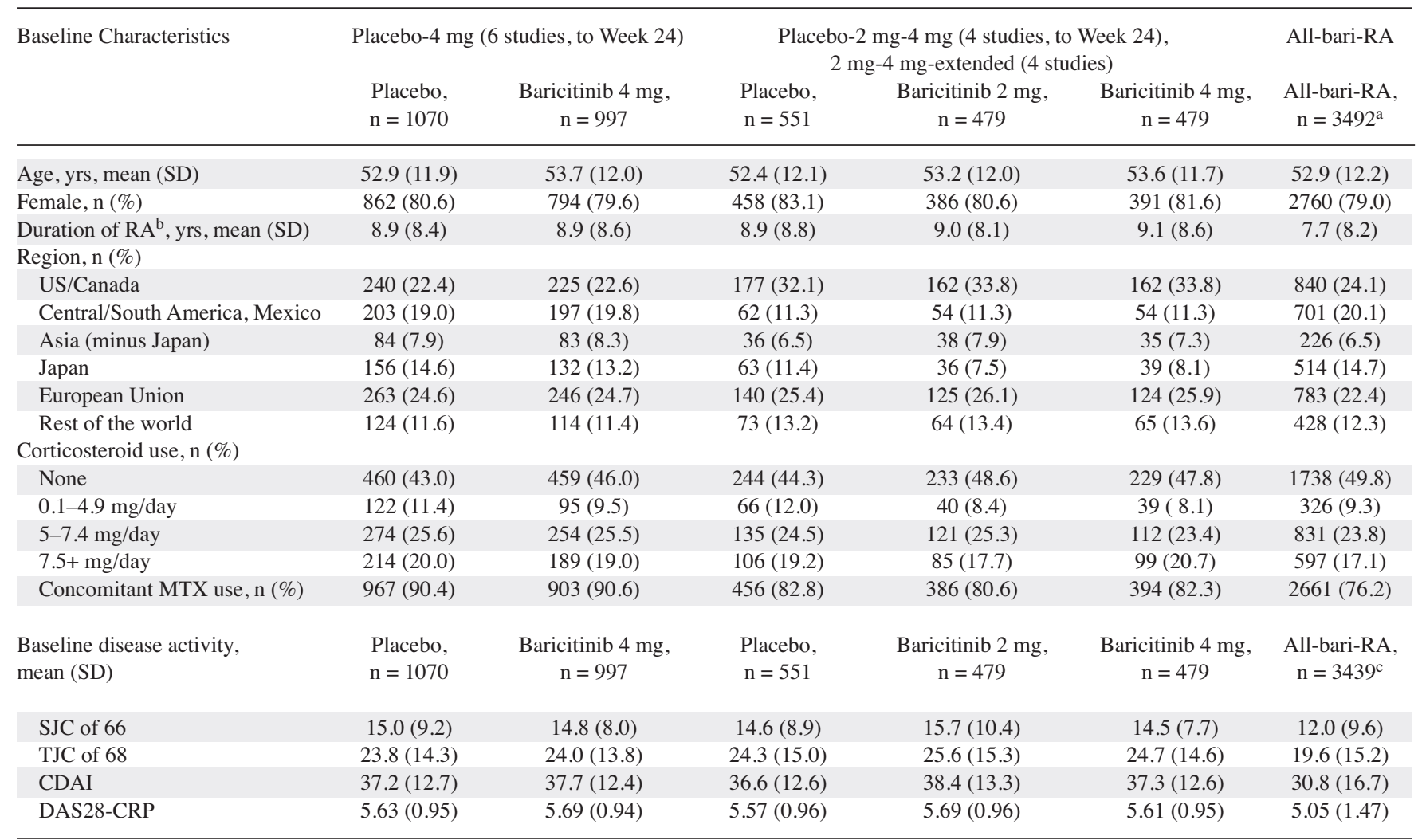

a All-bari-RA (patients who received any baricitinib dose) includes patients who switched from placebo, adalimumab, or MTX to baricitinib. Thus, it is a larger group than the 2-mg and 4-mg groups added together. ${ }^{b}$ Time from RA diagnosis. ${ }^{\mathrm{c}}$ The number for the all-bari-RA group is smaller for disease activity measures than for demographics because baseline disease activity measures are only available for phase II/III studies. RA: rheumatoid arthritis; MTX: methotrexate; CDAI: Clinical Disease Activity Index; DAS28-CRP: 28-joint count Disease Activity Score using high-sensitivity C-reactive protein; SJC: swollen joint count; TJC: tender joint count.

9\% (18/212) had multidermatomal distribution (> 3 contiguous or $\geq 2$ noncontiguous dermatomes), none had visceral involvement, and incidence did not increase over time (data not shown).

Malignancies. In the placebo versus $4 \mathrm{mg}$ analysis, the malignancy (excluding NMSC) IR was comparable between groups. In the $2 \mathrm{mg}-4 \mathrm{mg}$-extended analysis, the $4 \mathrm{mg}$ IR was numerically higher compared to $2 \mathrm{mg}$ with the "as-treated" analysis, while the "as-randomized" analysis showed a similar IR between $2 \mathrm{mg}$ and $4 \mathrm{mg}$ (Table 3). The all-bari-RA IR was 0.8 (95\% CI 0.6-1.0), with no increased incidence over time (Figure 1A). The age- and sex-adjusted standardized incidence ratio (SIR) based on Surveillance, Epidemiology, and End Results Program data ${ }^{21}$ was 1.04 (95\% CI 0.79-1.36).

To further quantify malignancy risk in all-bari-RA, we assessed patients who initiated and maintained $4 \mathrm{mg}(\mathrm{n}=$ $2658,4645 \mathrm{PY})$. In this all-bari-RA $4 \mathrm{mg}$ subcohort, the malignancy (excluding NMSC) IR was $0.8(95 \%$ CI $0.6-1.08)$.

The NMSC IR was higher for $4 \mathrm{mg}$ compared to $2 \mathrm{mg}$ in $2 \mathrm{mg}-4 \mathrm{mg}$-extended (Table 3 ), driven by a higher incidence diagnosed within 24 weeks of starting $4 \mathrm{mg}$ (Supplementary Table 2, available with the online version of this article). The all-bari-RA IR was 0.4 (95\% CI 0.2-0.5) and did not increase over time (Figure 1B).

No lymphoma cases were reported in the controlled periods, and 6 were reported during the LTE (all-bari-RA IR $0.09,95 \%$ CI $0.03-0.19$; Table 3 ). Four patients initially received placebo and switched/rescued to $4 \mathrm{mg}$; one initially received ADA and switched to $4 \mathrm{mg}$, and 1 initiated on $4 \mathrm{mg}$; patients received baricitinib for an average of 485 days (range 342-670 days) prior to lymphoma event. Lymphoma types included a gastric mucosa-associated lymphoid tissue B cell lesion ( $\mathrm{n}=1$, successfully treated with Helicobacter pylori eradication alone) and $B$ cell $(n=4)$ and $T$ cell $(n=1)$ lymphoma. Five of the 6 cases were taking background MTX, and the other was taking concomitant tacrolimus. Two cases of lymphoproliferative disorder were reported. One patient began taking ADA and was diagnosed 112 days after rescue to $4 \mathrm{mg}$. The other initiated with $4 \mathrm{mg}$ and was diagnosed after 259 days of treatment. As of last followup, corrective lymphoma treatment was not administered in either case. 
Table 3. Safety variables of special interest.

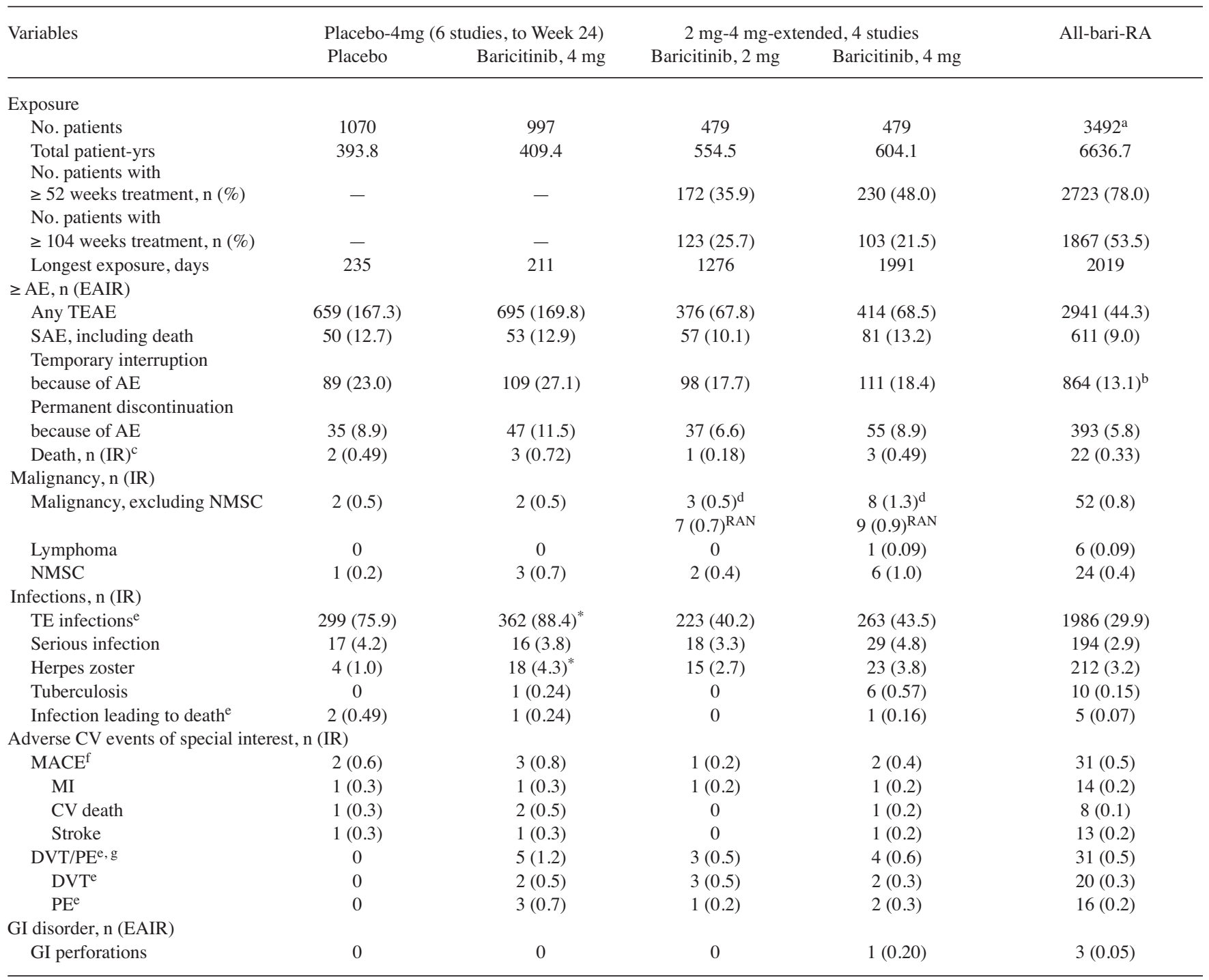

${ }^{*} \mathrm{p}<0.05$ for baricitinib $4 \mathrm{mg}$ vs placebo. P value from Cochran-Mantel-Haenszel percentage test stratified by study. EAIR were calculated as the number of unique patients with an event per 100 patient-years (PY) of overall exposure time. Incidence rates were calculated as the number of unique patients with an event per $100 \mathrm{PY}$ of observation time. ${ }^{\text {a }}$ All-bari-RA include patients who switched from placebo, ADA, or MTX to baricitinib. Thus, it is a larger group than the sum of the 2-mg and 4-mg groups. ${ }^{\mathrm{b}}$ Some studies did not collect temporary interruption of study drug. ${ }^{\mathrm{c}}$ Three deaths occurred among placebo-treated patients ( 2 infection, 1 stroke/CNS hemorrhage). One of the patients died 2 months after completing the 24-week placebo-controlled period, so that death is not included in the table. This patient never took the active study drug. Four deaths occurred among active-comparator-treated patients (1 ADA-treated patient from infection, 3 MTX-treated patients, 1 PE, 1 pulmonary fibrosis, 1 unwitnessed death), and 22 deaths occurred among baricitinib-treated patients [ 2 baricitinib $2 \mathrm{mg}$ ( 1 natural causes, 1 noninfectious acute respiratory failure); 10 baricitinib $\geq 4 \mathrm{mg}$ ( 3 malignancy, 2 infections, $1 \mathrm{PE}, 1$ stroke/CNS hemorrhage, $1 \mathrm{MI} / \mathrm{CAD}$, 1 non-CNS hemorrhage, 1 coagulopathy); and 10 patients after switch/rescue to baricitinib $4 \mathrm{mg}$ or entry to LTE period (3 MI/CAD, 3 infection, 1 stroke/CNS hemorrhage, 1 malignancy, 1 noninfectious acute respiratory failure, 1 unwitnessed death)]. ${ }^{\mathrm{d}}$ See Supplementary Table 2 for case summaries from the 2 mg- 4 mg-extended analysis set. RAN In the "as-randomized" analysis for malignancy excluding NMSC, all data were attributed to the initial randomized treatment group disregarding rescue or dose changes. The PY of observation times with the as-randomized analysis were 1055 and 1064 years for 2-mg and 4-mg groups, respectively, and 564 and 615 years for 2 and $4 \mathrm{mg}$, as-treated analysis. ${ }^{\mathrm{e}}$ Used exposure-adjusted incidence rates events/100 PY (patient exposure not censored at the event). ${ }^{\mathrm{f}}$ Potential CV AE from the phase III trials and LTE, identified by investigators or according to a predefined list of event terms, were adjudicated by an independent, external Clinical Endpoint Committee, which remained blinded to treatment assignments. ${ }^{\mathrm{g}}$ MedDRA-preferred terms of "deep vein thrombosis"/"pulmonary embolism" were analyzed without adjudication. After the September 2016 data cutoff, a followup medical review identified an additional event of DVT (termed thrombophlebitis) in the baricitinib 4-mg group during the placebo-controlled period. That event is not included in this table. EAIR: exposure-adjusted incidence rates; AE: adverse event; CV: cardiovascular; DVT: deep vein thrombosis; GI: gastrointestinal; NMSC: nonmelanoma skin cancer; MACE: major adverse cardiovascular events; MI: myocardial infarction; PE: pulmonary embolism; SAE: serious AE; TE: treatment-emergent; CAD: coronary artery disease; CNS: central nervous system; RA: rheumatoid arthritis; LTE: longterm extension; ADA: adalimumab; MTX: methotrexate; MedDRA: Medical Dictionary for Regulatory Activities.

Personal non-commercial use only. The Journal of Rheumatology Copyright $\subset$ 2019. All rights reserved. 
Table 4. Adverse events (AE) detail.

\begin{tabular}{|c|c|c|c|c|c|}
\hline \multirow[t]{2}{*}{ Variables } & \multicolumn{2}{|c|}{ Placebo-4mg (6 studies, to Week 24) } & \multicolumn{2}{|c|}{ 2mg-4mg-extended, 4 studies } & \multirow[b]{2}{*}{ All-bari-RA } \\
\hline & Placebo & Baricitinib $4 \mathrm{mg}$ & Baricitinib $2 \mathrm{mg}$ & Baricitinib $4 \mathrm{mg}$ & \\
\hline \multicolumn{6}{|l|}{$\begin{array}{l}\text { TEAE in } \geq 2 \% \text { of } 4 \mathrm{mg} \text {-treated } \\
\text { patients in placebo- } 4 \mathrm{mg}, \mathrm{n} \text { (EAIR) }\end{array}$} \\
\hline Nasopharyngitis & $67(17.0)$ & $68(16.6)$ & $39(7.0)$ & $53(8.8)$ & $433(6.5)$ \\
\hline Upper respiratory tract infection & $46(11.7)$ & $52(12.7)$ & $52(9.4)$ & $56(9.3)$ & $356(5.4)$ \\
\hline Urinary tract infection & $31(7.9)$ & $43(10.5)$ & $37(6.7)$ & $49(8.1)$ & $336(5.1)$ \\
\hline Bronchitis & $37(9.4)$ & $39(9.5)$ & $30(5.4)$ & $38(6.3)$ & $360(5.4)$ \\
\hline Hypercholesterolemia & $14(3.6)$ & $34(8.3)^{*}$ & $13(2.3)$ & $28(4.6)^{\dagger}$ & $172(2.6)$ \\
\hline Nausea & $20(5.1)$ & $32(7.8)$ & $21(3.8)$ & $21(3.5)$ & $162(2.4)$ \\
\hline Pharyngitis & $18(4.6)$ & $28(6.8)$ & $25(4.5)$ & $24(4.0)$ & $183(2.8)$ \\
\hline Diarrhea & $39(9.9)$ & $25(6.1)$ & $28(5.0)$ & $21(3.5)$ & $154(2.3)$ \\
\hline Anemia & $24(6.1)$ & $25(6.1)$ & $12(2.2)$ & $15(2.5)$ & $140(2.1)$ \\
\hline Cough & $21(5.3)$ & $21(5.1)$ & $20(3.6)$ & $21(3.5)$ & $156(2.4)$ \\
\hline Back pain & $28(7.1)$ & $20(4.9)$ & $28(5.0)$ & $24(4.0)$ & $207(3.1)$ \\
\hline $\mathrm{RA}$ & $30(7.6)$ & $15(3.7)^{*}$ & $15(2.7)$ & $23(3.8)$ & $158(2.4)$ \\
\hline \multicolumn{6}{|c|}{ Temporary interruption because of $\mathrm{AE} \geq 0.2 \mathrm{EAIR}$ for $4 \mathrm{mg}$-treated patients in placebo- $4 \mathrm{mg}, \mathrm{n}$ (EAIR) } \\
\hline Infections and infestations & $52(13.4)$ & $67(16.6)$ & $58(10.5)$ & $68(11.3)$ & $542(8.2)$ \\
\hline Gastrointestinal disorders & $8(2.1)$ & $11(2.7)$ & $7(1.3)$ & $11(1.8)$ & $79(1.2)$ \\
\hline Blood and lymphatic system disorders & $4(1.0)$ & $7(1.7)$ & $2(0.4)$ & $4(0.7)$ & $50(0.8)$ \\
\hline Investigations & $7(1.8)$ & $3(0.7)$ & $6(1.1)$ & $7(1.2)$ & $61(0.9)$ \\
\hline Vascular disorders & 0 & $3(0.7)$ & $5(0.9)$ & $2(0.3)$ & $16(0.2)$ \\
\hline Cardiac disorders & $1(0.3)$ & $2(0.5)$ & $3(0.5)$ & $2(0.3)$ & $23(0.3)$ \\
\hline $\begin{array}{l}\text { General disorders and administration } \\
\text { site conditions }\end{array}$ & $1(0.3)$ & $2(0.5)$ & $2(0.4)$ & $5(0.8)$ & $19(0.3)$ \\
\hline Renal and urinary disorders & $2(0.5)$ & $1(0.2)$ & $3(0.5)$ & $2(0.3)$ & $16(0.2)$ \\
\hline Reproductive system and breast disorders & 0 & $1(0.2)$ & $1(0.2)$ & 0 & $10(0.2)$ \\
\hline \multicolumn{6}{|c|}{ Permanent discontinuation because of $\mathrm{AE} \geq 0.2 \mathrm{EAIR}$ for $4 \mathrm{mg}$-treated patients in placebo- $4 \mathrm{mg}, \mathrm{n}$ (EAIR) } \\
\hline Infections and infestations ${ }^{\mathrm{a}}$ & $7(1.8)$ & $21(5.1)^{*}$ & $9(1.6)$ & $22(3.6)$ & $130(1.9)$ \\
\hline Investigations & $2(0.5)$ & $7(1.7)$ & $4(0.7)$ & $7(1.1)$ & $44(0.7)$ \\
\hline Cardiac disorders & $1(0.3)$ & $3(0.7)$ & $1(0.2)$ & 0 & $11(0.2)$ \\
\hline Blood and lymphatic system disorders & 0 & $2(0.5)$ & $5(0.9)$ & $3(0.5)$ & $36(0.5)$ \\
\hline $\begin{array}{l}\text { General disorders and administration site } \\
\text { conditions }\end{array}$ & 0 & $2(0.5)$ & $2(0.4)$ & $1(0.2)$ & $9(0.1)$ \\
\hline Immune system disorders & 0 & $2(0.5)$ & $1(0.2)$ & $2(0.3)$ & $2(0.0)$ \\
\hline Hepatobiliary disorders & $1(0.3)$ & $2(0.5)$ & $3(0.5)$ & $2(0.3)$ & $19(0.3)$ \\
\hline Neoplasms (benign, malignant, and unspecifie & & & & & \\
\hline including cysts and polyps) & $3(0.8)$ & $2(0.5)$ & $3(0.5)$ & $9(1.5)$ & $51(0.8)$ \\
\hline Ear and labyrinth disorders & 0 & $1(0.2)$ & 0 & $1(0.2)$ & $1(0.0)$ \\
\hline Gastrointestinal disorders & $4(1.0)$ & $1(0.2)$ & $3(0.5)$ & $1(0.2)$ & $18(0.3)$ \\
\hline Musculoskeletal and connective tissue & $6(1.5)$ & $1(0.2)$ & $1(0.2)$ & $2(0.3)$ & $13(0.2)$ \\
\hline Nervous system disorders & 0 & $1(0.2)$ & 0 & $1(0.2)$ & $8(0.1)$ \\
\hline Reproductive system and breast disorders & 0 & $1(0.2)$ & 0 & $1(0.2)$ & $2(0.0)$ \\
\hline Skin and SC tissue disorders & $2(0.5)$ & $1(0.2)$ & $1(0.2)$ & 0 & $4(0.1)$ \\
\hline
\end{tabular}

${ }^{*} \mathrm{p}<0.05$ for baricitinib $4 \mathrm{mg}$ versus placebo. ${ }^{\dagger} \mathrm{p}<0.05$ for baricitinib $2 \mathrm{mg}$ versus $4 \mathrm{mg}$. Adverse events are anchored in exposure-adjusted incidence rates (EAIR) of patients treated with $4 \mathrm{mg}$ in placebo-4 mg. EAIR were calculated as the no. unique patients with an event per 100 patient-years (PY) of overall exposure time. ${ }^{\text {a }}$ Most infections were due to herpes zoster. TEAE: treatment-emergent AE; SC: subcutaneous; RA: rheumatoid arthritis. 
Table 5. Changes in selected laboratory values and clinical chemistry (weeks 0-24). ${ }^{\mathrm{a}}$

\begin{tabular}{|c|c|c|c|c|c|}
\hline \multirow[b]{2}{*}{ Treatment-emergent shifts, n/NAR (\%) } & \multicolumn{2}{|c|}{ Placebo-4 mg (6 studies, to Week 24) } & \multicolumn{3}{|c|}{ Placebo-2 mg-4 mg (4 studies, to Week 24) } \\
\hline & Placebo & Baricitinib $4 \mathrm{mg}$ & Placebo & Baricitinib $2 \mathrm{mg}$ & Baricitinib $4 \mathrm{mg}$ \\
\hline $\mathrm{LDL}^{\mathrm{b}}, \geq 130 \mathrm{mg} / \mathrm{dl}$ & $70 / 517(13.5)$ & $243 / 577(42.1)^{*}$ & $35 / 225(15.6)$ & $77 / 264(29.2)^{\ddagger}$ & $89 / 248(35.9)$ \\
\hline Triglycerides, $\geq 500 \mathrm{mg} / \mathrm{dl}$ & 7/979 (0.7) & $5 / 943(0.5)$ & $5 / 497(1.0)$ & $5 / 444(1.1)$ & $1 / 444(0.2)$ \\
\hline \multicolumn{6}{|l|}{ Creatinine $^{\mathrm{b}}$} \\
\hline$>1 \mathrm{ULN}$ & $21 / 989(2.1)$ & 29/951 (3.0) & $12 / 484(2.5)$ & $12 / 444(2.7)$ & $18 / 441(4.1)$ \\
\hline \multicolumn{6}{|l|}{$\mathrm{CPK}^{\mathrm{b}}$} \\
\hline$>\mathrm{ULN}$ & $89 / 954(9.3)$ & $337 / 893(37.7)^{*}$ & $52 / 494(10.5)$ & $103 / 451(22.8)^{\ddagger}$ & $167 / 438(38.1)^{\dagger}$ \\
\hline$>2.5 \times \mathrm{ULN}$ & $14 / 1021(1.4)$ & $52 / 950(5.5)^{*}$ & $10 / 538(1.9)$ & $14 / 476(2.9)$ & $33 / 470(7.0)^{\dagger}$ \\
\hline$>5 \times$ ULN & $5 / 1028(0.5)$ & $11 / 956(1.2)$ & $5 / 543(0.9)$ & $5 / 476(1.1)$ & $8 / 474(1.7)$ \\
\hline \multicolumn{6}{|l|}{ Hemoglobin } \\
\hline$<$ LLN & $193 / 747(25.8)$ & $204 / 696(29.3)$ & $100 / 407(24.6)$ & $91 / 343(26.5)$ & $102 / 360(28.3)$ \\
\hline$<10 \mathrm{mg} / \mathrm{dl}$ & $63 / 1040(6.1)$ & $60 / 968(6.2)$ & $28 / 536(5.2)$ & $35 / 467(7.5)$ & $33 / 462(7.1)$ \\
\hline$<\mathrm{LLN}$ & 28/1030 (2.7) & $16 / 967(1.7)$ & $12 / 523(2.3)$ & $6 / 466(1.3)$ & $5 / 462(1.1)$ \\
\hline$>600,000 / \mathrm{mm}^{3}$ & $14 / 1055(1.3)$ & $23 / 983(2.3)$ & $9 / 542(1.7)$ & $7 / 472(1.5)$ & $13 / 473(2.7)$ \\
\hline \multicolumn{6}{|c|}{ Patients with any postbaseline elevation, $\mathrm{n} / \mathrm{N}(\%)^{\mathrm{a}}$ ALT } \\
\hline$>1 \mathrm{ULN}$ & $134 / 932(14.4)$ & $221 / 902(24.5)$ & $59 / 469(12.6)$ & $66 / 431(15.3)$ & $100 / 435(23.0)$ \\
\hline$\geq 3 \times \mathrm{ULN}$ & $14 / 1058(1.3)$ & $15 / 988(1.5)$ & $2 / 544(0.4)$ & $7 / 474(1.5)$ & $6 / 474(1.3)$ \\
\hline$\geq 5 \times \mathrm{ULN}$ & $4 / 1059(0.4)$ & $7 / 987(0.7)$ & $0 / 544$ & $3 / 477(0.6)$ & $4 / 474(0.8)$ \\
\hline$\geq 10 \times$ ULN $^{c}$ & $0 / 1059$ & 2/988 (0.2) & $0 / 544$ & $1 / 477(0.2)$ & $1 / 474(0.2)$ \\
\hline
\end{tabular}

${ }^{*} \mathrm{p}<0.05$ for baricitinib $4 \mathrm{mg}$ versus placebo. ${ }^{\ddagger} \mathrm{p}<0.05$ for baricitinib $2 \mathrm{mg}$ versus placebo. ${ }^{\dagger} \mathrm{p}<0.05$ for baricitinib $2 \mathrm{mg}$ versus $4 \mathrm{mg}$. $\mathrm{P}$ value from

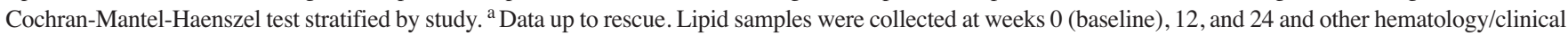
assessments were collected at weeks 0, 1, 2, 4, 8, 12, 14, 16, 20, and 24. National Cholesterol Education Program Adult Treatment Panel III guidelines (2002) were used for lipids ${ }^{19}$. Common Terminology Criteria for Adverse Events v3.0 were used for other laboratory variables ${ }^{20}$. ${ }^{\mathrm{b}}$ There were differences in laboratory assay methodologies and only the laboratory data collected using the same methodology were pulled, therefore the number of patients at risk can differ slightly across analytes. 'Of the 3 cases of ALT $\geq 10 \times$ ULN, 1 patient had cholecystitis (study RA-BEGIN), 1 patient was receiving isoniazid treatment (study RA-BEGIN), and 1 patient started methotrexate within 6 mos of randomization (study RA-BEAM). ALT: alanine aminotransferase; CPK: creatine phosphokinase; HDL: high-density lipoprotein; LDL: low-density lipoprotein; LLN: lower limit of normal; NAR: number at risk; ULN: upper limit of normal.

Gastrointestinal (GI) perforation. Three cases were reported in all-bari-RA (IR 0.05, 95\% CI 0.01-0.13; Table 3): a perforated appendix, a perforated diverticulum, and a proximal intestinal perforation after knee surgery. All patients were taking background MTX and nonsteroidal antiinflammatory drugs, and 2 were taking prednisone.

Major adverse cardiovascular event (MACE). The all-bariRA MACE IR was 0.5 (95\% CI 0.4-0.7; Table 3). The incidence of MACE and the individual components were comparable between groups.

Deep vein thrombosis $(D V T) /$ pulmonary embolism (PE). In placebo-4 mg, there were no cases of DVT/PE with placebo and 5 cases with $4 \mathrm{mg}$. One case occurred after discontinuing baricitinib, and 1 case resolved with continued administration of baricitinib and without anticoagulant treatment. In the remaining 3 cases, baricitinib was either continued or temporarily interrupted, then restarted without worsening or recurrence. Two of the 5 events were serious. All patients had multiple DVT/PE risk factors. After the September 2016 data cutoff, a followup medical review identified a sixth event of DVT (termed thrombophlebitis) in the baricitinib 4-mg group during the placebo-controlled period in a patient taking oral contraceptives. One fatal PE was reported with MTX monotherapy during the controlled period (Table 3, footnote c). In $2 \mathrm{mg}-4 \mathrm{mg}$-extended, the DVT/PE incidence was comparable between doses (IR $0.5 \mathrm{vs} 0.6,2 \mathrm{mg}$ vs $4 \mathrm{mg}$, respectively). Thirty-one patients reported DVT/PE in all-bari-RA (IR 0.5, 95\% CI 0.3-0.7) and the IR was stable over time (Supplementary Figure 1, available with the online version of this article). Independent association with VTE incidence was seen for increased age, increased body mass index, history of DVT/PE, and use of selective cyclooxygenase-2 inhibitors, but not for other factors such as baseline disease activity or corticosteroid use. To further quantify any potential DVT/PE risk, the 928 patients starting $4 \mathrm{mg}$ after placebo were assessed; 1 DVT was reported through 24 weeks of baricitinib treatment.

Laboratory and chemistry changes. In placebo-4 mg and placebo-2 mg-4 mg, no significant differences between treatment groups were observed for hemoglobin shifts to less than the lower limit of normal (LLN),$<10 \mathrm{~g} / \mathrm{dl}$, or $<8 \mathrm{~g} / \mathrm{dl}$ (Table 5). In the DMARD-inadequate responder $4 \mathrm{mg}$

Personal non-commercial use only. The Journal of Rheumatology Copyright $\subset$ 2019. All rights reserved. 
A

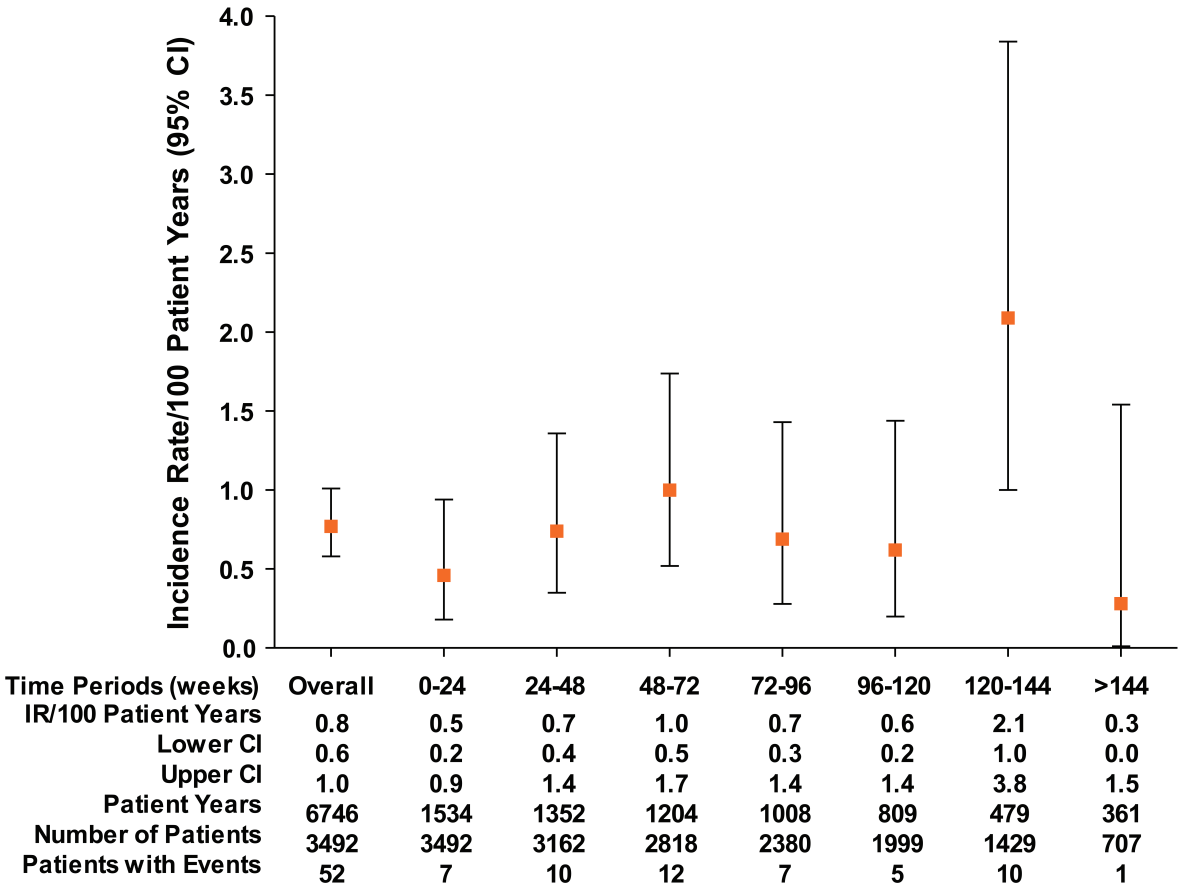

B

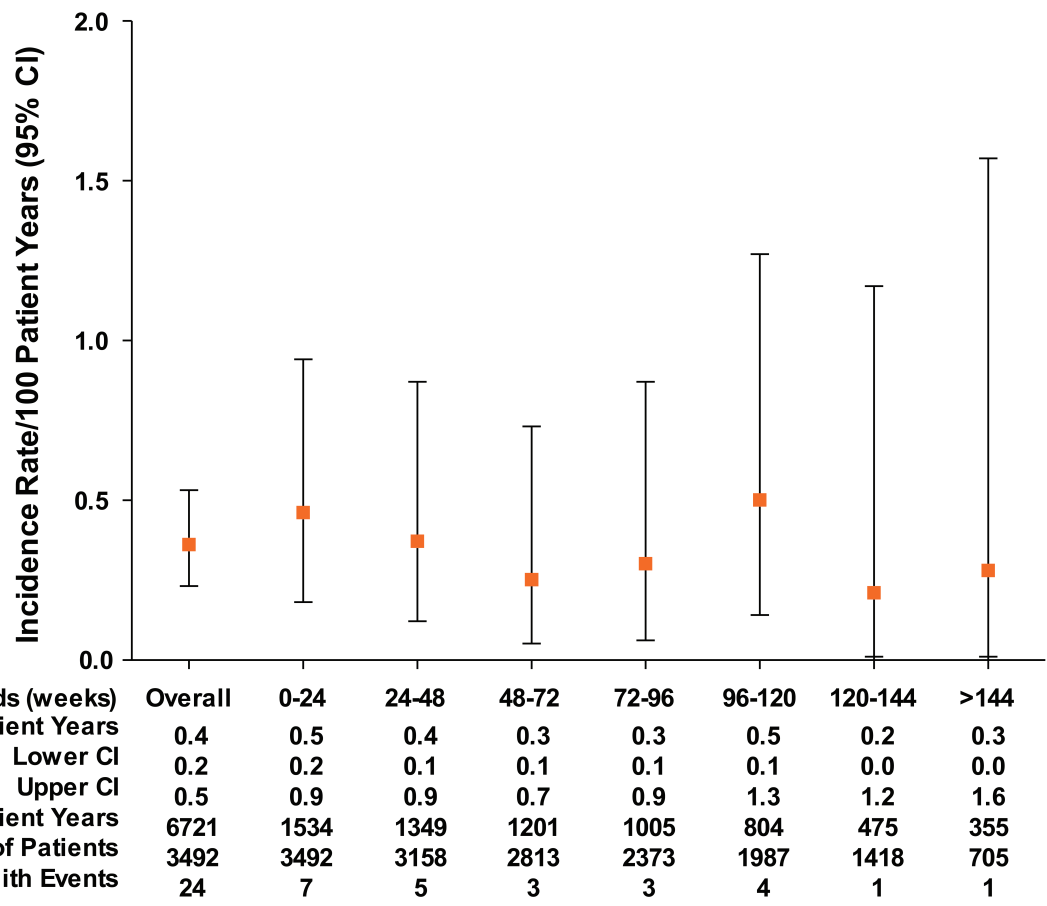

Figure 1. Malignancy-related events over time for all-bari-RA analysis set (IR). A. Cumulative incidence rate of malignancy (excluding NMSC) by time period for all-bari-RA patients (IR per $100 \mathrm{PY}$; 95\% CI). B. Cumulative incidence rate of NMSC by time period of report for all-bari-RA patients (IR per $100 \mathrm{PY}$; 95\% CI). RA: rheumatoid arthritis; IR: incidence rate; NMSC: nonmelanoma skin cancer; PY: patient-years.

longterm cohort, a small mean decrease from baseline in hemoglobin through Week 20 was observed, and returned to baseline or higher with continued treatment (Supplementary Figure 2A, available with the online version of this article).
In placebo-4 mg and placebo-2 mg-4 mg, no significant differences between treatment groups were observed for shifts in lymphocytes to $<500$ cells $/ \mathrm{mm}^{3}$, neutrophils to $<1000$ cells $/ \mathrm{mm}^{3}$, or platelets to $<$ LLN (Table 5). Mean 
lymphocyte and neutrophil count changes associated with longterm baricitinib treatment are shown in Supplementary Figure 2B-C. Lymphocyte counts initially increased, then declined to baseline. Neutrophil counts initially decreased within normality, then remained stable. Baricitinib $4 \mathrm{mg}$ was associated with a modest increase in mean platelet counts that peaked at 2 weeks, returned toward baseline and remained stable (Supplementary Figure 2D). A small proportion of patients had a platelet count $>600,000 / \mathrm{mm}^{3}$ (Table 5). No association was observed between platelet count increase $\geq 400,000 / \mathrm{mm}^{3}$ and DVT/PE (25.8\% vs $36.1 \%$ for patients with and without a DVT/PE).

Significant increases from baseline in low-density lipoprotein (LDL) to $\geq 130 \mathrm{mg} / \mathrm{dl}$ and high-density lipoprotein (HDL) to $\geq 60 \mathrm{mg} / \mathrm{dl}$ were observed with both doses (Table 5); however, LDL/HDL ratio did not change (mean: 0.01, -0.04 , and -0.01 ; placebo, $2 \mathrm{mg}, 4 \mathrm{mg}$, respectively). In general, LDL and HDL increased in the first 12 weeks and stabilized thereafter (data not shown). In baricitinib-treated patients, dose-dependent, largely asymptomatic increases in creatine phosphokinase (CPK) were observed. Discontinuation owing to increased CPK or muscle symptoms was uncommon $(0.2 \%)$, and the proportion of patients experiencing muscle symptoms did not differ across treatment groups.

Small mean increases $(<0.1 \mathrm{mg} / \mathrm{dl})$ in serum creatinine were observed with baricitinib within the initial weeks of treatment (Supplementary Figure 2E, available with the online version of this article). Elevations in alanine aminotransferase (ALT) $>$ upper limit of normal (ULN) were more frequent for baricitinib $4 \mathrm{mg}$ compared to placebo in placebo-4 $\mathrm{mg}$ and placebo-2 $\mathrm{mg}-4 \mathrm{mg}$ (Table 5; Supplementary Figure 2F). ALT elevations to $\geq 3 \times$ ULN were comparable across treatment groups while nondose-dependent elevations $\geq 5 \times \mathrm{ULN}$ were more frequent for baricitinib compared to placebo. In all-bari-RA, permanent discontinuations due to hepatobiliary AE were uncommon (EAIR 0.3; Table 4). No case met Hy's Law criteria for drug-induced liver injury ${ }^{22}$.

\section{DISCUSSION}

We report an assessment of baricitinib safety in patients with RA through 5.5 years of treatment. Our data suggest that the incidence of death, SAE including infections, and malignancy are similar to those observed for other therapeutic trials. Few patients discontinued as a result of adverse events.

The all-bari-RA mortality rate was similar to other RA therapeutic programs $23,24,25,26,27,28$. The clinical conditions contributing to death were common to patients with RA and none predominated (Table 3, footnote c).

Patients with RA are at elevated risk of infection from their disease ${ }^{29,30}$ and its therapies ${ }^{2,3,31}$. While a higher overall TE infection rate was observed with baricitinib $4 \mathrm{mg}$ vs placebo, serious infection rates were similar. The all-bari-RA serious infection rate was similar to other RA therapeutic trials $23,25,26,27,28,29,30,32$. Infections leading to death were uncommon (IR 0.07) in baricitinib-treated patients. TB was observed in baricitinib-treated patients. While tumor necrosis factor (TNF) inhibitors have been shown to increase TB risk $^{33,34}$, it is unclear whether JAK inhibitors have similar effects. In tofacitinib trials, most TB cases $(81 \%)$ occurred in endemic countries, and rates varied according to the general population's background TB rate ${ }^{35}$. This increased risk versus the general population is similar to that observed in real-world studies with TNF inhibitors ${ }^{33,36}$. TB screening prior to therapy should reduce risk ${ }^{17}$.

Although there was no observed increased risk for serious infections with baricitinib, there was an increased risk of herpes zoster (no visceral case), similar to that seen with other JAK inhibitors ${ }^{27,35,37,38}$ and higher than that observed with bDMARD ${ }^{39}$. Increased zoster risk with JAK inhibitors may result from inhibition of Type 1 interferons, which signal through a JAK1/tyrosine kinase 2 heterodimer. Dose-dependent increases in zoster risk without an increased risk for serious infections have been seen with Type 1 antiinterferon antibodies in patients with systemic lupus erythematosus ${ }^{40,41}$. This suggests an on-target mechanism, rather than generalized immune suppression, for increased zoster risk. Zoster vaccination for selected patients prior to initiating JAK inhibitors may be a therapeutic option ${ }^{36,42,43}$.

There were 52 malignancy cases (excluding NMSC). With short-term treatment, the IR between placebo and $4 \mathrm{mg}$ was similar. In $2 \mathrm{mg}-4 \mathrm{mg}$ extended, the $4 \mathrm{mg}$ IR was numerically higher compared to $2 \mathrm{mg}$. However, with "as-randomized" analysis, the IR between doses was similar. To account for long latency, as-randomized analysis does not censor data at rescue or dose change. Additionally, screening effects may lower the risk of uncommon/rare events in earlier phases of a trial ${ }^{15}$. As-randomized analysis reduces the bias introduced by postbaseline, unidirectional switching of patients from the lower to higher baricitinib dose (due to rescue). Lastly, the IR for both all-bari-RA and all-bari-RA $4 \mathrm{mg}$ subcohort of patients who initiated and maintained on $4 \mathrm{mg}$ was $0.8 / 100$ PY. The latter may represent a more accurate estimate for $4 \mathrm{mg}$ than that observed in $2 \mathrm{mg}-4 \mathrm{mg}$-extended because it is based on over 7-times more PY of exposure (4645 vs 604). Exposure time within baricitinib trials is relatively limited, and longer time periods will be needed to further evaluate malignancy risk. At present, the malignancy (excluding NMSC) IR appears to be similar to those reported in other RA therapeutic programs ${ }^{24,25,28,44,45}$ and remained stable over time. The SIR of 1.04 (95\% CI 0.79-1.36) indicates that the cancer IR in the baricitinib RA program is not increased compared to a similar United States population sample ${ }^{21}$.

Patients with RA are at an increased risk of DVT/PE ${ }^{46,47}$. In placebo-4 mg, DVT/PE were observed with $4 \mathrm{mg}$ but not placebo (5 vs 0 patients). Although a causal relationship to baricitinib cannot be excluded, traditional risk factors were

Personal non-commercial use only. The Journal of Rheumatology Copyright @ 2019 . All rights reserved. 
present in each case. Additionally, for patients converting from placebo to $4 \mathrm{mg}$, only 1 DVT case was reported in over 900 patients through 24 weeks of treatment. No dose or temporal dependency in DVT/PE risk was observed with prolonged administration. In all-bari-RA, the DVT/PE IR of $0.5 / 100 \mathrm{PY}$ was comparable with background rates of 0.3 to $0.8 / 100 \mathrm{PY}$ in real-world studies of the RA population $46,47,48$. Further study will be necessary to evaluate this potential risk.

Regarding other AE of special interest, the incidence of MACE was low. There were 3 GI perforations [IR of $0.05 / 100 \mathrm{PY}(0.5 / 1000 \mathrm{PY})]$, and the observed IR appears to be lower than that observed for tofacitinib, tocilizumab, and other bDMARD in real-world data (IR range 0.73 to $1.55 / 1000 \mathrm{PY})^{49}$.

Fewer than $1 \%$ of patients stopped baricitinib because of laboratory changes, and very few patients experienced Common Terminology Criteria for AE (CTCAE) grade $\geq 3$ changes in specific laboratory variables. While JAK selectivity of baricitinib differs from tofacitinib, the existing overlap likely explains the similarity in laboratory changes including increases in LDL, HDL, CPK, liver tests, and creatinine ${ }^{39}$. Additionally, with both compounds neutrophils drop after drug start, although this has not been correlated with an increased infection risk ${ }^{26}$. However, a similar small percentage of patients developed CTCAE grade 3 and 4 changes in lymphocytes between placebo and baricitinib arms, and overall, mean lymphocyte levels did not decrease over time with baricitinib use. While patients taking baricitinib had a small transient mean decrease in hemoglobin, the proportions of patients with abnormally low hemoglobin did not differ significantly between baricitinib and placebo, and very few experienced CTCAE grade $\geq 3$ changes $(<8 \mathrm{mg} / \mathrm{dl})$.

Limitations of this analysis include the short placebo-controlled period, which diminishes AE assessment of baricitinib versus the underlying disease, particularly for uncommon events (e.g., malignancy, MACE, DVT/PE) ${ }^{50}$. The IR of these uncommon events compared to published background rates provides context. Baricitinib 2-mg exposure was limited, although the 4-mg safety profile should inform that of $2 \mathrm{mg}$. Limitations of LTE studies include lack of a control arm, modification of background therapy according to clinicians' discretion, and variability of dosing such as rescue or taper. However, these factors more closely reflect usual clinical care; thus, the results could be applicable to real-world use.

We have evaluated the safety of baricitinib in over 3400 patients with RA treated for up to 5.5 years. Throughout its development, baricitinib was generally well tolerated. Infection risk, particularly for herpes zoster, is elevated as with other JAK inhibitors, and clinicians should take steps to prevent and monitor for such infections. Longterm risks of malignancy need further study, but currently there is no signal suggesting an increased risk. The potential risk for DVT/PE warrants further characterization, including in the postmar- keting setting. Overall, in the context of demonstrated efficacy $7,8,9,10$ in patients with active RA, baricitinib $4 \mathrm{mg}$ and $2 \mathrm{mg}$ once daily had an acceptable safety profile through up to 5.5 years of longterm exposure.

\section{ACKNOWLEDGMENT}

We thank the patients, investigators, and study staff who were involved in these studies. We also thank Cate Jones, PhD, Eli Lilly and Co., for assistance with tables, manuscript preparation, and process support, and Julie Sherman, AAS, Eli Lilly and Co., for assistance with figures.

\section{ONLINE SUPPLEMENT}

Supplementary material accompanies the online version of this article.

\section{REFERENCES}

1. Smolen JS, Aletaha D, McInnes IB. Rheumatoid arthritis. Lancet 2016;388:2023-38.

2. Furst DE. The risk of infections with biologic therapies for rheumatoid arthritis. Semin Arthritis Rheum 2010;39:327-46.

3. Ramiro S, Sepriano A, Chatzidionysiou K, Nam JL, Smolen JS, van der Heijde D, et al. Safety of synthetic and biological DMARDs: a systematic literature review informing the 2016 update of the EULAR recommendations for management of rheumatoid arthritis. Ann Rheum Dis 2017;76:1101-36.

4. Fridman JS, Scherle PA, Collins R, Burn TC, Li Y, Li J, et al. Selective inhibition of JAK1 and JAK2 is efficacious in rodent models of arthritis: preclinical characterization of INCB028050. J Immunol 2010;184:5298-307.

5. Iwata S, Tanaka Y. Progress in understanding the safety and efficacy of Janus kinase inhibitors for treatment of rheumatoid arthritis. Expert Rev Clin Immunol 2016;12:1047-57.

6. O'Shea JJ, Holland SM, Staudt LM. JAKs and STATs in immunity, immunodeficiency, and cancer. N Engl J Med 2013;368:161-70.

7. Taylor PC, Keystone EC, van der Heijde D, Weinblatt ME, De Carmen Morales L, Reyes Gonzaga J, et al. Baricitinib versus placebo or adalimumab in rheumatoid arthritis. N Engl J Med 2017;376:652-62.

8. Genovese MC, Kremer J, Zamani O, Ludivico C, Krogulec M, Xie $\mathrm{L}$, et al. Baricitinib in patients with refractory rheumatoid arthritis. N Engl J Med 2016;374:1243-52.

9. Dougados M, van der Heijde D, Chen YC, Greenwald M, Drescher $\mathrm{E}$, Liu J, et al. Baricitinib in patients with inadequate response or intolerance to conventional synthetic DMARDs: results from the RA-BUILD study. Ann Rheum Dis 2017;76:88-95

10. Fleischmann R, Schiff M, van der Heijde D, Ramos-Remus C, Spindler A, Stanislav M, et al. Baricitinib, methotrexate, or combination in patients with rheumatoid arthritis and no or limited prior disease-modifying antirheumatic drug treatment. Arthritis Rheumatol 2017;69:506-17.

11. Payne C, Zhang X, Shahri N, Williams W, Cannady E. Evaluation of potential drug-drug interactions with baricitinib [abstract]. J Managed Care Spect Pharm 2014;20:S51-2.

12. Keystone EC, Taylor PC, Drescher E, Schlichting DE, Beattie SD, Berclaz PY, et al. Safety and efficacy of baricitinib at 24 weeks in patients with rheumatoid arthritis who have had an inadequate response to methotrexate. Ann Rheum Dis 2015;74:333-40.

13. Tanaka Y, Emoto K, Cai Z, Aoki T, Schlichting D, Rooney T, et al Efficacy and safety of baricitinib in Japanese patients with active rheumatoid arthritis receiving background methotrexate therapy: A 12-week, Double-blind, Randomized Placebo-controlled Study. J Rheumatol 2016;43:504-11.

14. Aletaha D, Smolen J. The Simplified Disease Activity Index (SDAI) and the Clinical Disease Activity Index (CDAI): a review of their

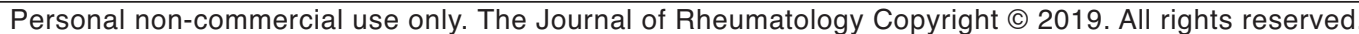


usefulness and validity in rheumatoid arthritis. Clin Exp Rheumatol 2005;23(5 Suppl 39):S100-8.

15. Rothman KJ. A potential bias in safety evaluation during open-label extensions of randomized clinical trials. Pharmacoepidemiol Drug Saf 2004;13:295-8.

16. Baber N. International conference on harmonisation of technical requirements for registration of pharmaceuticals for human use (ICH). Br J Clin Pharmacol 1994;37:401-4.

17. Singh JA, Saag KA, Bridges SL Jr, Akl AE, Bannuru RR, Sullivan MC, et al. 2015 American College of Rheumatology guideline for the treatment of rheumatoid arthritis. Arthritis Rheumatol 2016;68:1-26.

18. Anderson J, Caplan L, Yazdany J, Robbins ML, Neogi T, Michaud $\mathrm{K}$, et al. Rheumatoid arthritis disease activity measures: American College of Rheumatology recommendations for use in clinical practice. Arthritis Care Res 2012;64:640-7.

19. Third report of the National Cholesterol Education Program (NCEP) expert panel on detection, evaluation, and treatment of high blood cholesterol in adults (Adult Treatment Panel III) final report. Circulation 2002;106:3143-421.

20. National Cancer Institute. DCTD, Division of Cancer Treatment and Diagnosis. CTEP, Cancer Therapy Evaluation Program. Common terminology criteria for adverse events, Version 3.0 (CTCAE). [Internet. Accessed July 20, 2018.] Available from: ctep.cancer.gov/protocolDevelopment/electronic_applications/ctc.htm

21. Howlader N, Noone AM, Krapcho M, Miller D, Bishop K, Kosary CL, Yu M, et al, editors. SEER Cancer Statistics Review, 1975-2014, National Cancer Institute. [All Cancer Sites (Invasive) Age-Specific SEER Incidence Rates, 2010-2014, Table 2.7] Bethesda, Maryland. Based on November 2016 SEER data submission, posted to the SEER Web site April 2017. [Internet. Accessed July 20, 2018.] Available from: seer.cancer.gov/csr/1975_2014

22. U.S. Department of Health and Human Services, Food and Drug Administration, Center for Drug Evaluation and Research (CDER), Center for Biologics Evaluation and Research (CBER). Guidance for industry on drug-induced liver injury: premarketing clinical evaluation. July 2009. [Internet. Accessed July 20, 2018.] Available from: www.fda.gov/downloads/guidances/UCM174090.pdf

23. Klareskog L, Gaubitz M, Rodriguez-Valverde V, Malaise M, Dougados M, Wajdula J, et al. Assessment of long-term safety and efficacy of etanercept in a 5-year extension study in patients with rheumatoid arthritis. Clin Exp Rheumatol 2011;29:238-47.

24. Gottlieb AB, Gordon K, Giannini EH, Mease P, Li J, Chon Y, et al. Clinical trial safety and mortality analyses in patients receiving etanercept across approved indications. J Drugs Dermatol 2011;10:289-300

25. Schiff MH, Kremer JM, Jahreis A, Vernon E, Isaacs JD, van Vollenhoven RF. Integrated safety in tocilizumab clinical trials. Arthritis Res Ther 2011;13:R141.

26. Wollenhaupt J, Silverfield J, Lee EB, Curtis JR, Wood SP, Soma K, et al. Safety and efficacy of tofacitinib, an oral Janus kinase inhibitor, for the treatment of rheumatoid arthritis in open-label, long-term extension studies. J Rheumatol 2014;41:837-52.

27. Cohen SB, Tanaka Y, Mariette X, Curtis JR, Lee EB, Nash P, et al. Long-term safety of tofacitinib for the treatment of rheumatoid arthritis up to 8.5 years: integrated analysis of data from the global clinical trials. Ann Rheum Dis 2017;76:1253-62.

28. Burmester GR, Panaccione R, Gordon KB, McIlraith MJ, Lacerda AP. Adalimumab: long-term safety in 23458 patients from global clinical trials in rheumatoid arthritis, juvenile idiopathic arthritis, ankylosing spondylitis, psoriatic arthritis, psoriasis and Crohn's disease. Ann Rheum Dis 2013;72:517-24.

29. Doran MF, Crowson CS, Pond GR, O'Fallon WM, Gabriel SE. Frequency of infection in patients with rheumatoid arthritis compared with controls: a population-based study. Arthritis Rheum 2002; 46:2287-93

30. Listing J, Gerhold K, Zink A. The risk of infections associated with rheumatoid arthritis, with its comorbidity and treatment. Rheumatology 2013;52:53-61.

31. Boyle DL, Soma K, Hodge J, Kavanaugh A, Mandel D, Mease P, et al. The JAK inhibitor tofacitinib suppresses synovial JAK1-STAT signalling in rheumatoid arthritis. Ann Rheum Dis 2015;74:1311-6.

32. Genovese MC, Schiff M, Luggen M, Becker JC, Aranda R, Teng J, et al. Efficacy and safety of the selective co-stimulation modulator abatacept following 2 years of treatment in patients with rheumatoid arthritis and an inadequate response to anti-tumour necrosis factor therapy. Ann Rheum Dis 2008;67:547-54.

33. Dixon WG, Hyrich KL, Watson KD, Lunt M, Galloway J, Ustianowski A, et al. Drug-specific risk of tuberculosis in patients with rheumatoid arthritis treated with anti-TNF therapy: results from the British Society for Rheumatology Biologics Register (BSRBR). Ann Rheum Dis 2010;69:522-8.

34. Winthrop KL, Novosad SA, Baddley JW, Calabrese L, Chiller T, Polgreen $\mathrm{P}$, et al. Opportunistic infections and biologic therapies in immune-mediated inflammatory diseases: consensus recommendations for infection reporting during clinical trials and postmarketing surveillance. Ann Rheum Dis 2015;74:2107-16.

35. Winthrop KL, Park SH, Gul A, Cardiel MH, Gomez-Reino JJ, Tanaka Y, et al. Tuberculosis and other opportunistic infections in tofacitinib-treated patients with rheumatoid arthritis. Ann Rheum Dis 2016;75:1133-8.

36. Seong SS, Choi CB, Woo JH, Bae KW, Joung CL, Uhm WS, et al. Incidence of tuberculosis in Korean patients with rheumatoid arthritis (RA): effects of RA itself and of tumor necrosis factor blockers. J Rheumatol 2007;34:706-11.

37. Yamaoka K. Benefit and risk of tofacitinib in the treatment of rheumatoid arthritis: A focus on herpes zoster. Drug Saf 2016; 39:823-40

38. Cohen S, Radominski SC, Gomez-Reino JJ, Wang L, Krishnaswami $\mathrm{S}$, Wood SP, et al. Analysis of infections and all-cause mortality in phase II, phase III, and long-term extension studies of tofacitinib in patients with rheumatoid arthritis. Arthritis Rheumatol 2014;66:2924-37.

39. Winthrop KL. The emerging safety profile of JAK inhibitors in rheumatic disease. Nat Rev Rheumatol 2017;13:234-43.

40. Khamashta M, Merrill JT, Werth VP, Furie R, Kalunian K, Illei GG, et al. Sifalimumab, an anti-interferon-alpha monoclonal antibody, in moderate to severe systemic lupus erythematosus: a randomised, double-blind, placebo-controlled study. Ann Rheum Dis 2016;75:1909-16

41. Furie R, Khamashta M, Merrill JT, Werth VP, Kalunian K, Brohawn $\mathrm{P}$, et al. Anifrolumab, an anti-interferon-alpha receptor monoclonal antibody, in moderate-to-severe systemic lupus erythematosus. Arthritis Rheumatol 2017;69:376-86

42. Harpaz R, Ortega-Sanchez IR, Seward JF. Prevention of herpes zoster: recommendations of the Advisory Committee on Immunization Practices (ACIP). MMWR Recomm Rep 2008; 57:1-30; quiz CE2-4.

43. van Assen S, Agmon-Levin N, Elkayam O, Cervera R, Doran MF Dougados $\mathrm{M}$, et al. EULAR recommendations for vaccination in adult patients with autoimmune inflammatory rheumatic diseases. Ann Rheum Dis 2011;70:414-22.

44. Curtis JR, Lee EB, Martin G, Mariette X, Terry KK, Chen Y, et al. Analysis of non-melanoma skin cancer across the tofacitinib rheumatoid arthritis clinical programme. Clin Exp Rheumatol 2017;35:614-22.

45. Curtis JR, Lee EB, Kaplan IV, Kwok K, Geier J, Benda B, et al. Tofacitinib, an oral Janus kinase inhibitor: analysis of malignancies across the rheumatoid arthritis clinical development programme.

Personal non-commercial use only. The Journal of Rheumatology Copyright (C) 2019. All rights reserved. 
Ann Rheum Dis 2016;75:831-41.

46. Kim SC, Schneeweiss S, Liu J, Solomon DH. Risk of venous thromboembolism in patients with rheumatoid arthritis. Arthritis Care Res 2013;65:1600-7.

47. Ogdie A, Kay McGill N, Shin DB, Takeshita J, Jon Love T, Noe $\mathrm{MH}$, et al. Risk of venous thromboembolism in patients with psoriatic arthritis, psoriasis and rheumatoid arthritis: a general population-based cohort study. Eur Heart J 2017 Apr 20 (E-pub ahead of print).

48. Romero-Diaz J, Garcia-Sosa I, Sanchez-Guerrero J. Thrombosis in systemic lupus erythematosus and other autoimmune diseases of recent onset. J Rheumatol 2009;36:68-75.
49. Xie F, Yun H, Bernatsky S, Curtis JR. Brief report: risk of gastrointestinal perforation among rheumatoid arthritis patients receiving tofacitinib, tocilizumab, or other biologic treatments. Arthritis Rheumatol 2016;68:2612-7.

50. U.S. Department of Health and Human Services, Food and Drug Administration, Center for Drug Evaluation and Research (CDER), Center for Biologics Evaluation and Research (CBER). May 2001. Guidance for industry: E 10 choice of control group and related issues in clinical trials. [Internet. Accessed July 20, 2018.] Available from: www.fda.gov/downloads/drugs/guidancecomplianceregulatory information/guidances/ucm073139.pdf 


\section{Correction}

\section{Safety Profile of Baricitinib in Patients with Active Rheumatoid Arthritis with over 2 Years Median Time in Treatment}

Smolen JS, Genovese MC, Takeuchi T, Hyslop DL, Macias WL, Rooney T, et al. Safety profile of baricitinib in patients with active rheumatoid arthritis with over 2 years median time in treatment. J Rheumatol 2019;46:7-18.

In Table 1, Phase II, NCT01469013 is mentioned twice. The second occurrence is unnecessary.

In the Results section, page 9, last paragraph, the first sentence should read as follows: "The herpes zoster IR was significantly higher for $4 \mathrm{mg}$ compared to placebo (4.3 vs 1.0) and was numerically higher for $4 \mathrm{mg}$ compared to 2 $\mathrm{mg}$ in $2 \mathrm{mg}-4 \mathrm{mg}$-extended." Bold face indicates words added for clarity.

Table 4. Adverse events (AE) detail.

- Three AE (EAIR $\geq 0.2$ ) and their data have been added under the category "Temporary interruption because of
$\mathrm{AE} \geq 0.2 \mathrm{EAIR}$ for $4 \mathrm{mg}$-treated patients in placebo- 4 mg, n (EAIR)." See below.

- Under the category "Permanent discontinuation because of AE $\geq 0.2$ EAIR for $4 \mathrm{mg}$-treated patients in placebo-4 $\mathrm{mg}, \mathrm{n}$ (EAIR)," in the row for infections and infestations, under the $2 \mathrm{mg}-4 \mathrm{mg}$-extended set, for baricitinib $4 \mathrm{mg}$, the $\mathrm{p}$ value is $<0.05$, indicating significance.

Table 5. The corrected table is below. Changes are indicated in bold face.

- HDL numbers have been corrected.

- Units for hemoglobin were corrected to $\mathrm{g} / \mathrm{dl}$.

- Hemoglobin $<10 \mathrm{~g} / \mathrm{dl}$ : the corrected values for baricitinib $2 \mathrm{mg}$ and baricitinib $4 \mathrm{mg}$ under the Placebo-2 mg-4 mg set are 33/462 (7.1) and 35/467 (7.5), respectively.

- In the Placebo-4 mg set, under Baricitinib $4 \mathrm{mg}$, the corrected values for ALT $\geq 3 \times$ ULN are 15/987 (1.5), and for ALT $\geq 5 \times$ ULN, 7/988 (0.7).

doi:10.3899/jrheum.171361.C1

Table 4. Additional data.

\begin{tabular}{|c|c|c|c|c|c|}
\hline \multirow[t]{2}{*}{ Variables } & \multicolumn{5}{|c|}{ Placebo-4mg (6 studies, to Week 24)2mg-4mg-extended, 4 Studies } \\
\hline & Placebo & Baricitinib $4 \mathrm{mg}$ & Baricitinib $2 \mathrm{mg}$ & Baricitinib $4 \mathrm{mg}$ & All-bari-RA \\
\hline \multicolumn{6}{|c|}{ Temporary interruption because of AE $\geq 0.2$ EAIR for $4 \mathrm{mg}$-treated patients in placebo- $4 \mathrm{mg}, \mathrm{n}$ (EAIR) } \\
\hline Skin and subcutaneous tissue disorders & $2(0.5)$ & $6(1.5)$ & $2(0.4)$ & $5(0.8)$ & $26(0.4)$ \\
\hline Respiratory thoracic and mediastinal disorders & $2(0.5)$ & $5(1.2)$ & $6(1.1)$ & $6(1.0)$ & $49(0.7)$ \\
\hline Surgical and medical procedures & $2(0.5)$ & $4(1.0)$ & $4(0.7)$ & $8(1.3)$ & $65(1.0)$ \\
\hline
\end{tabular}

AE: adverse events; EAIR: exposure-adjusted incidence rates; bari: baricitinib; RA: rheumatoid arthritis. 
Table 5 (Corrected). Changes in selected laboratory values and clinical chemistry (weeks $0-24){ }^{\text {a }}$

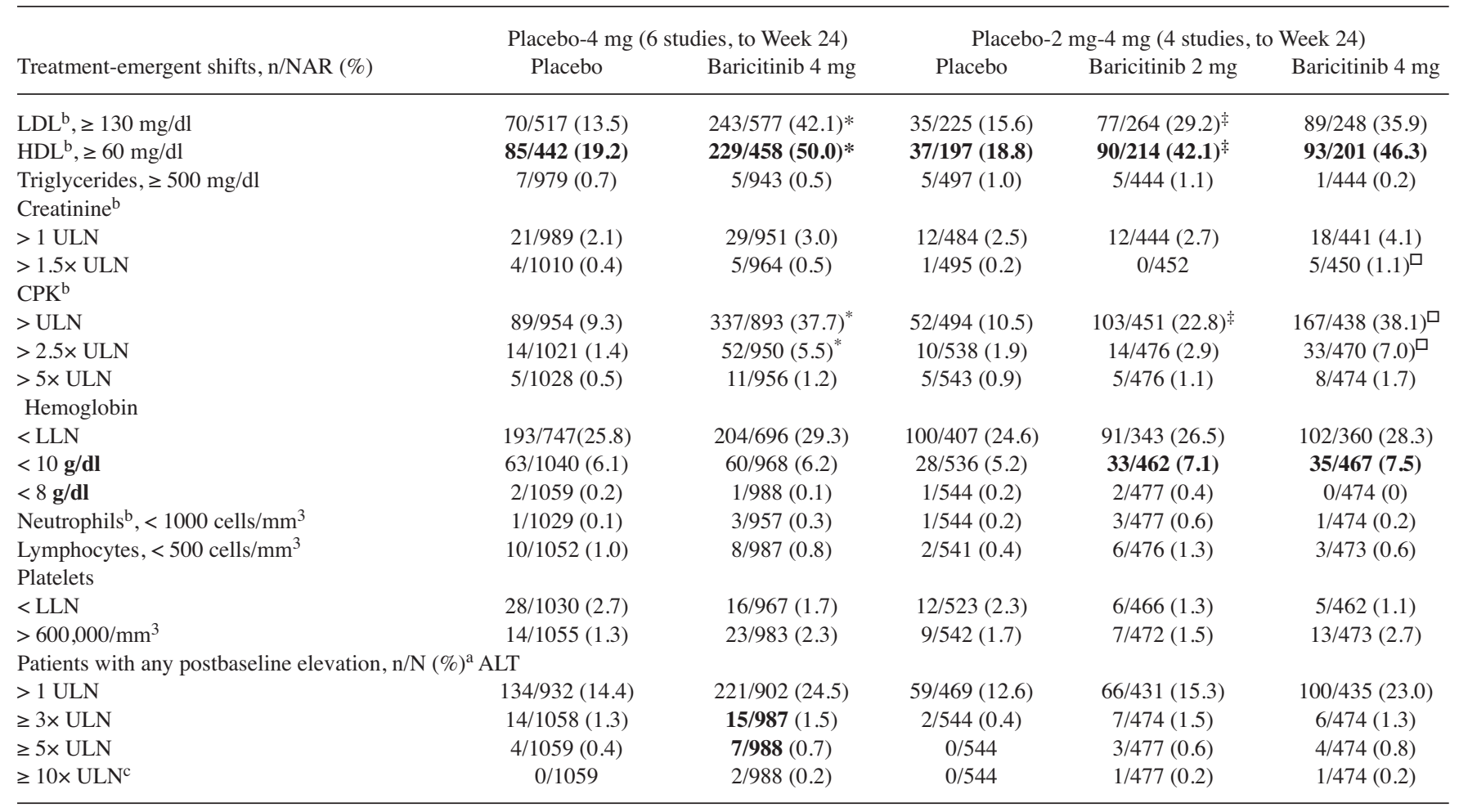

$* \mathrm{p}<0.05$ for baricitinib $4 \mathrm{mg}$ versus placebo. ${ }^{\ddagger} \mathrm{p}<0.05$ for baricitinib $2 \mathrm{mg}$ versus placebo. ${ }^{\square} \mathrm{p}<0.05$ for baricitinib $2 \mathrm{mg}$ versus $4 \mathrm{mg}$. P value from Cochran-Mantel-Haenszel test stratified by study. ${ }^{\text {a }}$ Data up to rescue. Lipid samples were collected at weeks 0 (baseline), 12, and 24, and other hematology/clinical assessments were collected at weeks 0, 1, 2, 4, 8, 12, 14, 16, 20, and 24. National Cholesterol Education Program Adult Treatment Panel III guidelines (2002) were used for lipids ${ }^{19}$. Common Terminology Criteria for Adverse Events v3.0 were used for other laboratory variables ${ }^{20}$. ${ }^{\mathrm{b}}$ There were differences in laboratory assay methodologies and only the laboratory data collected using the same methodology were pulled, therefore the number of patients at risk can differ slightly across analytes. ${ }^{\mathrm{c}}$ Of the 3 cases of ALT $\geq 10 \times \mathrm{ULN}, 1$ patient had cholecystitis (study RA-BEGIN), 1 patient was receiving isoniazid treatment (study RA-BEGIN), and 1 patient started methotrexate within 6 months of randomization (study RA-BEAM). ALT: alanine aminotransferase; CPK: creatine phosphokinase; HDL: high-density lipoprotein; LDL: low-density lipoprotein; LLN: lower limit of normal; NAR: number at risk; ULN: upper limit of normal. 